\title{
Sobre el Ceceo y el Seseo en Hispanoamérica
}

\begin{abstract}
A invitarme a colaborar en este Homenaje, sus organizadoA res me han pedido expresamente que exponga mis puntos de vista sobre la discutida cuestión del andalucismo en el español de América. Voy a ceñirme a uno de sus aspectos, el de la confusión entre $s$ y $c, z$. Intentar revisarlo no implica merma en la admiración que por la figura de Pedro Henríquez Ureña guardamos hoy cuantos, de un lado u otro del Atlántico, recibimos en nuestra juventud la lección de sus magistrales escritos.
\end{abstract}

En 1932, cuando publicó la versión definitiva de su estudio Sobre el problema del andalucismo dialectal de América el conocimiento previo que se tenía del andaluz era muy somero: la bibliografía científicamente aprovechable se limitaba a los artículos, ya lejanos, de Schuchardt y de Wulff, aparte de alguna certera observación de Américo Castro. En cuanto al español de América, apenas había empezado a salir la Biblioteca de Dialectología Hispanoamericana, con todo lo que supuso de aportaciones y revisión. La tesis andalucista tenía que parecer, forzosamente, producto de una impresión superficial no apoyada en razones sólidas. A combatir sus fallos se dedicaron Henríquez Ureña y otro gran desaparecido, Amado Alonso. Es justo reconocer que en muchos puntos los argumentos de uno y otro estaban bien construídos sobre los datos que entonces se poseían. Estadísticas sobre la procedencia de las gentes que pașaron a Indias en el siglo xvi no arrojaban predominio andaluz. Se creía que la confusión andaluza entre 
$s s, s$ y $c, z$ no había surgido hasta 1570 , por las mismas fechas en que se iniciaba la americana como fenómeno paralelo al andaluz, pero no ligado a él. Esta independencia se entendía manifiesta en el hecho de que en América no se hubiera registrado el ceceo, tenido como la pronunciación más característica y pujante en Andalucía.

Las noticias que hoy se tienen hacen variar por completo el planteamiento del problema. Ahora poseemos nutrida prueba documental de que el cambio andaluz estaba ya en marcha al tiempo de los viajes colombinos y primeras colonizaciones: el mismo Amado Alonso publicó buen número de testimonios. ${ }^{1}$ Otros nuevos recogidos por mí, obligan a conceder que el fenómeno tenía ya gran vitalidad a fines del siglo $\mathrm{XV}$, aunque no triunfase en todos los ambientes de Sevilla hasta 1560-70, conforme a la repetida cita de Arias Montano. Tanto la confusión siseante en $/ s /$ coronal o predorsal, como la ciceante en $/ \theta / 0 / \theta /$ fueron en su origen variedades del ceceo, pues tales articulaciones descienden de las antiguas de $s$ y $z$, no de las eses ápicoalveolares. Tal es la razón de que hasta el siglo XVII la confusión andaluza fuese denominada siempre çeçeo o zezeo, mientras que para la valenciana, que extendió las eses ápicoalveolares a costa de $\varsigma$ y $z$, se usaba el nombre de seseo. Sólo desde el siglo XVIII se aplica seseo a una variedad de la pronunciación andaluza, la igualación en $/ s /$ coronal o predorsal, y se reserva el de ceceo para la igualación en $/ \theta /$ o $/ \theta / .^{2}$

Históricamente lo que hoy se llama seseo americano fue, como el andaluz, "çeçeo" o "zezeo", pues consistió en la sustitución de la $s$ ápicoalveolar cóncava por la coronal o predorsal convexas resultantes de las antiguas $\varsigma, z$. No es exacto que en América falten variedades ciceantes análogas a las que ahora se entienden por ceceo andaluz: investigaciones dialectológicas hechas en los últimos años han señalado la existencia de unificación ciceante en Puerto Rico, Colombia, El Salvador,

1 Historia del "ceceo" y del "seseo" españoles, Thesavrvs, Bol. del Inst. Cato y Cuervo, VII, 1951.

2 Resumo aquí lo que digo en el artículo Sobre el ceceo y el seseo andaluces, próximo a aparecer en el Homenaje a André Martinet que publicará la Universidad de La Laguna. 
Nicaragua y Argentina. ${ }^{3}$ Seguramente aparecerán en otros países. Sin embargo, la pronunciación que domina en el español de América es la siseante con / $s$ / coronal o predorsal; pero en esto Hispanoamérica no difiere de la ciudad de Sevilla, Norte de su provincia, Córdoba con toda la suya y ciertas zonas de Huelva, Málaga y Jaén; además en el resto de la Andalucía confundidora la dicción siseante es más fina y urbana, la ciceante más rústica y vulgar. ${ }^{4}$

Dada la prelación cronológica del cambio en Sevilla y la costa, se ve que su forma más admitida fue la que se irradió a Córdoba y demás regiones andaluzas de población asentada, mientras la masa que desde la Andalucía Occidental se desplazó al caer el reino moro de Granada, para instalarse en Málaga, Oeste granadino y Sur de Almería, llevó consigo la forma más vulgar. El crecimiento de la unificación siseante en América es paralelo y contemporáneo de la propagación del cambio sevillano a Guadalcanal, Córdoba o Antequera, siseantes también; y procede, sin duda, del mismo foco. Se podrá objetar que a diferencia de estas ciudades y comarcas, en América no se trata propiamente de una irradiación, sino, como vamos a ver, de un trasplante migratorio inicial; pero la posterior incorporación de una mayoría antes distinguidora hizo que el proceso americano tomase igual rumbo que el cordobés. Después volveremos sobre ello.

Veamos la proporción de andaluces en la colonización de América. Las estadísticas hechas por Henríquez Ureña en 1932 arrojaban sólo 4,695 andaluces en un total de 13,948 españoles y portugueses pasados a las Indias Occidentales antes de $1600,{ }^{5}$ lo que suponía sólo un $33.7 \%$. Pero los datos de que disponía Henríquez Ureña eran demasiado pobres; además

3 T. Navarro, El español en Puerto Rico, 1948, p. 69; Luis Flórez, La pronunciación del español en Bogotá, 1951, pp. 183-189; D. L. Canfield, Andalucismos en la pronunciación salvadoreña, Hispania, XXXVI, 1953, pp. 32-33; Heberto Lacayo, Apuntes sobre la pronunciación del español de Nicaragua, Ibid., XXXVII, 1954, pp. 267-268 (con minuciosa descripción fonética); y Berta Elena Vidal de Battini, El español en la Argentina, 1954, p. 68. Además Canfield me comunica que también se oye ceceo en Honduras y Venezuela.

4 T. Navarro Tomás, A. M. Espinosa, hijo, y L. Rodríguez Castellano, La frontera del andaluz, Rev. de Filol. Esp., XX, 1933, págs. 225-277.

5 Sobre el problema del andalucismo dialectal de América, 1932, p. 112. 
no separó los distintos momentos de la emigración. Pronto estará al alcance de los estudiosos una extensa monografía de Peter Boyd-Bowman sobre La procedencia regional de los primitivos colonizadores españoles de América, ${ }^{6}$ llena de noticias concluyentes; operando con una masa documental tres veces mayor que Henríquez Ureña, Boyd-Bowman llega al resultado de que en los primeros años del período antillano (1493-1508) hubo mayoría de emigrantes andaluces, y que en el decenio siguiente (1509-1519) las andaluzas excedieron a todo el resto del elemento femenino que pasó a Indias. En las Antillas, por lo tanto hubo de formarse un sedimento lingüístico andaluzado que constituyó la base del ulterior español de América.

No he podido examinar documentación bien editada de este período inicial antillano para ver si los amanuenses daban prueba escrita de que cundía allí la confusión de $\xi$ y $z$ con $s s$ y $s$. Aparece ya en escrituras mejicanas desde 1525; ya lo hice saber años atrás. ${ }^{7}$ En efecto, ojeando el Indice $y$ extractos de los Protocolos del Archivo de Notarías de México publicado por A. Millares Carlo y J. I. Mantecón, ${ }^{8}$ encuentro en el tomo I rrazo 'raso' y calsas (p. 30), çecuçión (p. 31), piesas, ortalisa (p. 39), calsada (p. 55), sinquenta (p. 60), desysorios, faser, desir, rrasonar (p.67), Badaxós (p. 79), señidor (p. 91), todos en documentos de 1525; en 1527, haser (p. 101), frizada 'frisada', (p. 111), vesyno (p. 113 y 115), asyón 'acción' (p. 116), ocupasyón (p. 125), Baltazar, pasyficar (p. 126), tosinos (p. 145), çeron 'serón' (p. 174), rrusya, rrusyo (p. 179), alcansastes (p. 180), dies (p. 184), Peres, crusifijo (p. 186), etc.; en 1528 ensima (p. 225), cabesadas (p. 260), cazamiento

6 Lo va a publicar el Instituto de Cultura Hispánica. Muy interesante es el estudio de José Pérez Vidal, Aportación de Canarias a la población de América (Anuario de Estudios Atlánticos, Madrid-Las Palmas, 1955, núm. 1), con la importante advertencia de que gran parte de los pasajeros que durante la primera mitad del siglo Xvi embarcaban en Canarias para América no eran isleños, sino extremeños y andaluces, sobre todo de la Andalucía atlántica (p. 74). No me ocupo ahora del seseo canario, atestiguado en el siglo xvir, pero no explorado aún en documentos anteriores.

7 En la segunda edición de mi Historia de la lengua española, 1950, p. 329.

8 El Colegio de México, 1945-46. Los ejemplos de confusión siguen apareciendo en el tomo II, año 1936: diesmos, mays (p. 23), baser, ruasón (p. 55), dies e seys (p. 69), etc. 
'casamiento' (p. 287), y otros más, aparte de mays, muy retirado, y de numerosas repeticiones. Es indudable que el estado de confusión que revelan tales grafías no pudo producirse en los cuatro años escasos que habían transcurrido entre la conquista de Méjico y los ejemplos más antiguos. Los amanuenses habían llegado allí resabiados ya, bien de las Antillas, bien directamente de la Andalucía occidental. Nótese que sus yerros, como en la documentación sevillana a fines del siglo $\mathrm{XV}$ y primeros del XVI, ofrecen ya cumplida la confusión de sibilantes en sus tres etapas: 1) en posición implosiva (Badaxós, mays, dies, Peres); 2) entre sonoras intervocálicas (rrazo, frizada, ortalisa, tosino, etc.) ; y 3), entre sordas (calsas, çecuçión, piesas, señidor, etc.).

Amado Alonso ha puesto de relieve la nivelación del lenguaje como fenómeno peculiar y decisivo en la vida colonial. ${ }^{9}$ Puedo aportar un ejemplo muy antiguo, demostrativo de lo contagiosa que era la confusión andaluza de sibilantes al tiempo de formarse la koiné lingüística americana. Se trata del conquistador y cronista Bernal Díaz del Castillo: nacido en Medina del Campo, pasó a Indias en 1514 y escribió su Historia verdadera de la conquista de la Nueva España hacia 1568, en Guatemala, cuando llevaba más de cincuenta años en tierras americanas. ${ }^{10}$ Ese medio siglo largo había dejado profunda huella en su lenguaje: el manuscrito autógrafo de la Historia verdadera muestra una confusión de sibilantes inconcebible en un castellano que no hubiera perdido su dicción nativa. Usa Bernal Díaz $z$ por $s$ implosiva y viceversa (marquez, Bazco, pas, gasnate, bes 'vez', pezcar, Cortez, Velasques, Gutierres); ${ }^{11}$ equivoca $s$ y $z$ intervocálicas (rriquesa, quize, artezas, sasón, brazeros 'braseros', rresio, azidos 'asidos', flechasos, payzes, pueblesuelos, mohozas, rresién $)^{12}$ intercambia ç con $s$ -

9 Estudios lingǘsticos. Temas bispanoamericanos, 1955, págs. 112 y sigs.

10 Me refiero a la fecha en que Bernal Díaz declara "estoy trasladando esta mi relación", aunque la composición de la obra se hubiera iniciado antes de 1557 y aunque haya adiciones posteriores. Véase Ramón Iglesia, Introducción ul estudio de B. D. del C. $y$ de su Verdadera Historia, en su libro El bombre Colón y otros ensayos, México, 1944, págs. 99-118.

i1 Ed. Genaro García, México, 1904, I, pp. 3, 8, 11, 18, 21, 30, 31, 52, 63.

12 Ibid., pp. 3, 7, 10, 14, 15, 18, 25, 31, 47, 55. 
o -ss- (abonansó, conosieron, sertificaba, serca, ençenada, acaeser, çed 'sed', sercana, çer, cierpes, vacallos, grandíçima), ${ }^{13}$ y su castellanismo le lleva a acelerar la simplificación fonemática ensordeciendo las sonoras y equiparándolas con las sordas (rreçina, proviçiones, zuele, Alonzo). ${ }^{14} \mathrm{Si}$ queremos saber qué influencias hicieron que Bernal Díaz abandonara la distinción entre eses, cedilla y zeta, en su misma obra econtraremos el rastro: el viejo soldado nos habla en ella de su convivencia con gentes como aquel capitán Luis Marín, natural de Sanlúcar, que "çeçeava un poco como sebillano", o aquellos tres pilotos que en 1517 llevaron al autor y a sus compañeros desde Cuba hasta el Yucatán: "el más prencipal... se dezía Antón de Alaminos, natural de Palos, y el otro se dezía Camacho de Triana, y el otro piloto se llamava Joan Álvarez el manquillo, natural de Güelva".15

Amado Alonso ha estudiado la acomodación de otros dos peninsulares al ambiente lingüístico del Nuevo Mundo. Los dos pertenecen a generaciones posteriores a la de Bernal Díaz: son el alférez guipuzcoano Francisco Ortiz de Vergara, que en 1569 llevaba treinta y tres años en el Río de la Plata, y el poeta Fernán González de Eslava, que salió de España en 1558, a la edad de veinticuatro años, y tuvo actividad literaria en Méjico entre esa fecha y $\mathbf{1 5 7 9}$ por lo menos. ${ }^{16}$ Los dos ofrecen en sus autógrafos muestras de confusión entre las sibilantes que nos ocupan; pero en Vergara se limitan al final de palabra, y en Eslava, si alcanzan los tres mismos grados que las escrituras notariales de 1525-1528, ${ }^{17}$ no tienen la abrumadora frecuencia que en Bernal Díaz, ni revelan ensordecimiento de $-s-\mathrm{y} z$. Estado parecido al de Eslava presentan las Flores de varia poesía, cancionero reunido en Méjico en 1577:

13 Ibid., pp. 10,12,13,16,17,18, 20, 28, 33, 35, 42, etc.

14 Ibid., pp. 47, 54, 17.

15 Ed. de [Ramón Iglesia y A. Rodríguez Moñino], Madrid, C. S. I. C., 1940 , p. 4, col. 2.

16 Estudios lingüisticos. Temas bispanoam. pp. 115-122; Biografia de F. G. de Eslava, RFH, II, 1940, pp. 266-268.

117 En posición implosiva, mez "mes, "Pero Dius"; sonoras intervocálicas, desiseis, rimas bizo-aviso, gozes-dioses, etc.; sordas, profeçión, conçejo. 
en él se tropieza a menudo con grafías como ançias, seño 'ceño', cerenos, sierra 'cierra', sielo, sierua 'cierva', auzente, asertaste, alcansaste, soçiega, sicalados 'acicalados', cançado, has (imperativo).$^{18} \mathrm{Es}$ seguro que los documentos mejicanos de 15251528 no reflejan todavía un uso general; pero cuarenta o cincuenta años después el testimonio conjunto de Bernal Díaz, Eslava y las Flores prueba que la práctica confundidora de $\varsigma, z$ y $s s, s$, trasplantada a Méjico en los días mismos de la conquista o a raíz de ella, se había convertido en hábito dominante, que se contagiaba allí a peninsulares no castellanos.

La antigüedad y empuje de la confusión de sibilantes en América fueron anteriores a lo que se ha venido admitiendo. Hubo sin duda un fermento lingüístico inicial, formado en el período antillano bajo el predominio numérico de andaluces y conservado luego en actividad con elementos de igual procedencia, aunque minoritarios ya en las nuevas migraciones. La asimilación de los no andaluces empezó en los primeros tiempos de la colonización y continuó durante siglos. Esa constante incorporación de gentes que originariamente distinguían entre $\varsigma, z$ y $s s, s$ explica la orientación tomada por el fenómeno en Hispanoamérica: triunfó allí la confusión sevillana, lo que en el siglo XVI se entendía por çeçeo o zezeo, pues las articulaciones ápico-alveolares cóncavas propias de $s$ y $s s$ fueron eliminadas en beneficio de las dentales o dento-alveolares convexas nacidas del aflojamiento de $z \mathrm{y} c$. Pero, lo mismo que en Córdoba y otras comarcas de Andalucía, la variedad de çeçeo o zezeo que arraigó fue la menos llamativa, la menos vulgar: es decir, el siseo con $/ s$ / coronal o predorsal, no el ciceo con $/ \theta . /$ o con $/ \theta /$; dicho de otro modo, lo que hoy clasificamos como seseo, no lo que hoy llamamos ceceo. Los actuales focos de este ceceo registrados en América pueden ser restos de un estado fluctuante que tal vez existiera antaño, o fruto de evolución autóctona y moderna de la $s$ convexa dental.

El paralelo, tan traído y llevado, del español de América con el latín vulgar resulta cierto, entre otros aspectos, en la propagación de dialectalismos metropolitanos a las nuevas pro-

18 Códice 2973 de la Biblioteca Nacional de Madrid, fols. 63, 167, 197, 201, $202,215,300-308$ (verso 172), 334-341 (verso 131), 381, etc., etc. 
vincias. La tesis de Menéndez Pidal, según la cual el latín hablado en España fue rico en dialectalismos itálicos meridionales se ve robustecida cada día con nuevos argumentos; ${ }^{19}$ la anticipación de fechas para la transformación de las sibilantes en Andalucía, y la temprana documentación del mismo cambio al otro lado del Atlántico, refuerzan la teoría andalucista sobre el seseo americano. El esperado trabajo de Paul Aebischer acerca de los colonizadores romanos de Hispania y el ya citado de Boyd-Bowman sobre los de la América española en el siglo XVI llevarán la evidencia a los espíritus más remisos.

RAFAEL LAPESA.

Universidad de Madrid.

19 Véase su estudio A propósito de l y ll latinas. Colonización suditálica en España. Bol. de la Real Academia Española, XXXIV, 1954, pp. 165-216; y rambién Serafim da Silva Neto, Fontes do Latim Vulgar, 1946, págs. 45 y sigts., e História da Lingua Portuguesa (en curso de publicación desde 1952), págs. 117, 122-124, etc. 